\title{
That Sinking Feeling, Again? The State of National Institutes of Health Pediatric Research Funding, Fiscal Year 1992-2010
}

\author{
DANIEL P. GITTERMAN AND WILLIAM W. HAY, JR \\ Department of Public Policy [D.P.G.], University of North Carolina at Chapel Hill, Chapel Hill, North Carolina; Department of \\ Pediatrics [W.W.H.], University of Colorado School of Medicine, Aurora, Colorado
}

\begin{abstract}
This review article examines the National Institutes of Health's (NIH) overall budget and its pediatric research funding across three time periods: predoubling [fiscal year (FY) 1992-1997]; doubling (FY 1998-2003); and postdoubling (FY 2004-2009). The average annual NIH appropriations increased by $5.4 \%, 13.4 \%$, and $1.3 \%$ in each period, respectively. The average annual pediatric research funding (actual grants, contracts, intramural research, and other mechanisms of support) increased much less, by $4.7 \%, 11.5 \%$, and $0.3 \%$ in each period, respectively. Between FY 2004 and FY 2007, the average NIH budget increase has nearly flattened, to only $1.96 \%$. During this period, average pediatric research funding has dropped markedly lower, to $0.57 \%$; estimated FY 2008 pediatric funding is at negative $0.5 \%$. Although pediatric research enjoyed significant benefits of the NIH doubling era, the proportion of the NIH budget devoted to the pediatric research portfolio has declined overall. The most recent period has wiped out the annual gains of the doubling era for both pediatric and overall NIH research funding. We offer recommendations to protect against further erosion of pediatric research funding and to implement several unfulfilled commitments to strengthen the federal pediatric research portfolio in the coming decade. (Pediatr Res 64: 462-469, 2008)
\end{abstract}

$\mathrm{T}$ The allocation of US federal budget outlays to the needs of children is a major area of interest for policymakers, child advocacy groups, clinical pediatricians, and academic pediatric researchers. Until recently, no comprehensive estimates of federal expenditures on children were available. ${ }^{1}$ In an important March 2007 study, the Urban Institute reported on trends in federal funding on children from 1960 to 2017 of more than 100 major federal programs, including the federal income tax. $^{2}$ The study noted that in 1960, children's share of domestic federal spending was roughly $20 \%$ (or $\$ 53$ billion of $\$ 263$ billion). By 2006, its share of the total was little more than $15 \%$. Thus, as a percent of federal domestic spending, chil-

Received June 12, 2008; accepted July 21, 2008.

Correspondence: Daniel P. Gitterman, Ph.D., University of North Carolina at Chapel Hill, Department of Public Policy, Abernethy Hall (202b), CB 3435, Chapel Hill, NC 27599-3435; e-mail: danielg@email.unc.edu

${ }^{1}$ Some estimates were provided by Jason Juffras and Eugene Steuerle to the National Commission on Children in 1991, and more detailed data were compiled in Clark R, Berkowitz R 1995 Federal expenditures on children, 1960-1995 (an unpublished report to the Assistant Secretary for Planning and Evaluation, Department of Health and Human Services).

${ }^{2}$ Children were defined as individuals under 19 years of age who are not yet engaged in postsecondary education. dren's spending declined during this period. In 2006, children represented $26 \%$ of the population (1). By 2017, current projections indicate that children's share of domestic federal spending will drop to about $13 \%$ (2). This analysis concludes that children are a "diminishing" national priority.

Prior scholarly efforts to analyze funding on children at National Institutes of Health (NIH) focused only on the flow of dollars to academic pediatric departments rather than on overall pediatric research funding as an independent category (3-5). With a specific interest in the status of the federal pediatric research portfolio, Gitterman et al. (2004) reported on trends in pediatric research funding in absolute terms and relative to the NIH budget, with a specific focus on the doubling period [fiscal year (FY) 1998-2003] when congressional appropriations increased from $\$ 13.6$ billion to $\$ 27.1$ billion. The intent in this report was to avoid interpreting funding as a competition between diseases that impact children versus adults but to report on how the NIH pediatric research portfolio fared in comparison with the overall budget during the doubling era (6).

The current review is a new systematic effort to examine historical and recent trends in funding of pediatric research at the NIH, including the predoubling, during, and postdoubling periods. We define the NIH pediatric research portfolio as the total funds obligated to conduct or support pediatric research across NIH. NIH has an obligation to respond to public health needs (including those of pediatric populations), but calculating these needs is very difficult. During the doubling of its budget (FY 1998-2003), NIH pediatric research funding increased by an average annual growth rate of $12.8 \%$, almost on

Abbreviations: BRDPI, biomedical research and development price index; CHA, children's health act; FY, fiscal year; ICs, institutes and centers; K-Awards, NIH career development awards; NRSA, NIH national research service award; NRSA F32, NIH postdoctoral individual fellowships; OD, NIH office of the director; PASs, NIH program announcements with set asides; PR-LRP, NIH extramural pediatric research loan repayment program; R21, NIH exploratory/developmental research grant award; RFAs, NIH requests for applications; RFPs, NIH requests for proposals; RPGs R01, NIH research project grant program; SBIR/STTR, NIH small business innovation research/small business technology transfer grant; T32, institutional research training grants 
par with the overall NIH average annual increase of $14.7 \%$. Between FY 2004 and FY 2007, the average annual NIH budget increase nearly flattened, to only $1.96 \%$. During this same time, however, the average annual increase for pediatric research funding dropped markedly lower, to $0.57 \%$; estimated FY 2008 pediatric funding is lower still at negative $0.5 \%$. Although NIH appropriations and pediatric research funding increased in nominal amounts, the proportion devoted to pediatrics has remained flat, as it has done since FY 1993.

We do not attempt to determine whether the amount of funding that NIH awards for research on pediatric diseases is commensurate with measures of the burden of disease (prevalence, incidence, use of resources and costs, mortality, morbidity, etc.) (7). We try to quantify pediatric research funding to assess progress, but it is important to use caution in drawing conclusions about decreases in pediatric research funding without accounting for the benefits of nonage-specific biomedical research, which are often spread over subpopulations in undifferentiated ways. Although important new initiatives have focused on a range of both rare and common pediatric conditions, our main conclusion is a need to increase the future support for pediatric biomedical research and to expand the number of opportunities for advancement in scientific investigations and care for children. Pediatricians will need to offer new conceptual arguments and evidence about the longer term benefits for tomorrow's adults of today's investment in the health and well-being of our pediatric populations.

\section{Methods, Data, and Policy Significance}

Basic science and adult research studies represent the majority of initiatives funded by the NIH $(8,9)$. However, in the mid-1990s, Congress expressed its concern about the "inadequate attention and resources devoted to pediatric research conducted and supported by NIH" (10). Congress specifically requested that the NIH develop performance indicators to measure its progress toward achieving a stronger pediatric research portfolio. In response, the NIH issued its first report on Pediatric Research in April 1996, including a summary of major pediatric research activities and a stated commitment "to use a variety of methods to evaluate their [NIH institutes and centers (IC's)] progress in achieving a strengthened portfolio in research on children" (11). Specific performance indicators, other than the annual planning process and consultation with ICs National Advisory Councils, were not discussed. In FY 1995, the NIH Budget Office (OB) directed all of its ICs to report total funding (including grants, contracts, and intramural support) related to pediatric disease and other crosscutting research areas. ${ }^{3}$ The NIH defines pediatric research as "studies in all categories of biomedical research (basic, clinical, epidemiologic, behavioral, prevention, treatment, diagnosis, as well as outcomes and health services) that relate to diseases, conditions, or the health/development of

\footnotetext{
${ }^{3} \mathrm{NIH}$ categorizes its funding in a variety of manners to satisfy diverse reporting requirements. Funding is tracked for specific diseases (Alzheimer's disease, breast cancer, etc.), for various conditions (infertility, obesity, etc.) and specific areas of research (genetics, substance abuse, etc.). See, http://www.nih.gov/news/fundingresearchareas.htm
}

neonates, infants, children, and adolescents up to age 21." $\mathrm{All}$ data reported in the figures were provided by the NIH OB.

In an attempt to address some of the ongoing deficits in the pediatric research portfolio, Congress - under the 2000 Children's Health Act (CHA) - authorized an "expansion, intensification, and coordination" of NIH activities with respect to pediatric research. ${ }^{5}$ The NICHD was designated as the lead institute on a number of the initiatives, including establishment of a pediatric research initiative (PRI), expansion of autism-related and Fragile X syndrome research activities, and conducting a national longitudinal study of environmental influences on child health (National Children' Study or "NCS"). ${ }^{6}$ Congress established the PRI to increase support for pediatric research, enhance collaborative efforts among ICs, speed the development of pediatric clinical drug trials, and invest in training pediatric researchers through a loan repayment program. Because a major component of the longstanding mission of the Eunice Kennedy Shriver NICHD is to improve and promote children's health and development, the NIH Director requested the NICHD Director to oversee and coordinate the PRI at the NIH and to coordinate preparation of the annual report on the status of the pediatric research portfolio (new and continuing grants and contracts).

Congress required NIH to report annually on the PRI and the total funds that ICs award for pediatric research (12). ${ }^{7}$ The NIH Inter-Institute Committee on Pediatric Research, created to encourage the development of new initiatives and collaboration, defined the PRI (a subset of all pediatric research) as only new research initiated by ICs and significant expansions of existing research funded for the first time in a reporting year (initiatives for which ICs had set aside specified amounts of available funds). ${ }^{8}$ "Significant expansions" could include increases in funding for an existing IC initiative to expand its size or scope beyond that for which funds were originally committed. An expansion could add a grant or site to an existing initiative, expand or add a pediatric population to an existing study, establish a collaboration with other ICs to enhance pediatric research, or award pediatric research career development grants beyond an IC's regular pay line. It is important to note that PRI reporting does not capture the additional IC obligations for new and expanded pediatric research projected that are investigator initiated. The March 2008 NIH Report to Congress on the FY 2006 PRI represents the most recent public reporting on NIH funding (13).

\footnotetext{
${ }^{4}$ NICHD internal memo on definition of research on children, June 12, 1997.

${ }^{5}$ The Children's Health Act of 2000 (P.L. 106-310) merged a number of individual bills and provisions into one piece of legislation.

${ }^{6}$ The National Children's Study (NCS) would allow a comprehensive, life course, developmental approach to tracing the influences of genetic and other biological, social, environmental, and behavioral factors on human development, health, and disease from conception onward.

${ }^{7}$ The CHA directed the OD to: “...be responsible for the oversight of any newly appropriated Initiative funds and annually report to Congress and the public on the extent of the total funds obligated to conduct or support pediatric research across the National Institutes of Health, including the specific support and research awards allocated through the Initiative [PRI]" (Sec. 409D(c)(3), the Public Health Service Act).

${ }^{8}$ For example (i.e., requests for applications or RFAs, requests for proposals or RFPs, and program announcements with set asides or PASs.)
} 


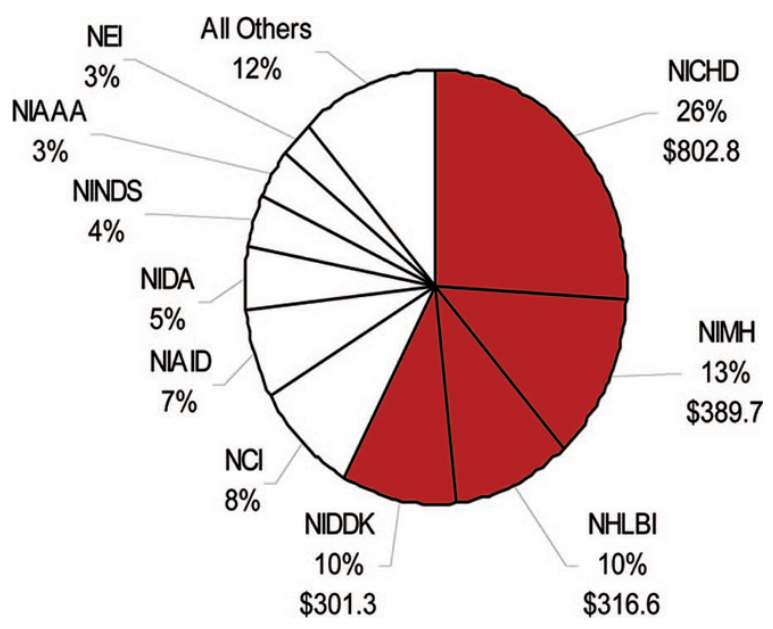

Figure 1. National Institutes of Health Pediatric Research Funding by Institute/Center (in millions and/or by percentage), fiscal year (FY) 2008. National Institutes of Health FY 2008 pediatric research funding total is $\$ 3.2$ billion (estimate).

\section{The State of the Pediatric Research Portfolio at NIH}

In FY 2008, 22 ICs invested in a NIH pediatric research portfolio of $\$ 3.2$ billion, a significant increase from the $\$ 1.7$ billion distributed across 18 ICs in FY 1993. As Figure 1 shows, although the NICHD is often viewed as the principal institute for the "profession of pediatric research," NICHD accounted for only a quarter of total NIH pediatric research funding. ${ }^{9}$ Nonetheless, in FY 2008, 64.6\% of NICHD's overall budget ( $\$ 424.9$ million) was awarded to pediatric research—by far the highest proportion of all the ICs. The NICHD's proportion of total pediatric research funding has remained relatively constant at 26\% (since FY 1993) and the three ICs (NICHD, NIMH, and NHLBI) with the largest pediatric research portfolio have been the same since FY 1993.

The "predoubling" era, FY 1993-1997. In 1994, except for double-digit increases for research on AIDS and breast cancer, the NIH faced a budget that was static or contracting in real dollars (14). In the "predoubling" era (FY 1992-1997), the overall NIH budget increased by an average annual growth rate of $7.5 \%$. The increase for pediatric research funding was considerably lower, only $4.7 \%$, and actually decreased as a proportion of the total NIH budget from 14.4 to $12.6 \%$ (Fig. 2). Directives in the FY 1996 House and Senate Appropriation committees' reports encouraged NIH to "strengthen its pediatric portfolio of basic, behavioral, and clinical research conducted and supported" by relevant ICs. The 1996 Report on NIH Pediatric Research offered an initial summary of the pediatric research portfolio, including problems associated with low birth weight and prematurity, birth defects and developmental problems, chronic and infectious diseases of childhood, childhood cancers, and environmental risks to the health of children.

The doubling era, FY 1998-2003. Congress (and the president) agreed to double funding for the NIH between FY 1998

\footnotetext{
${ }^{9}$ NICHD's pediatric funding excludes all reproductive, behavioral, demographic, and rehabilitation research not specifically aimed at improving the health of pediatric populations.
}

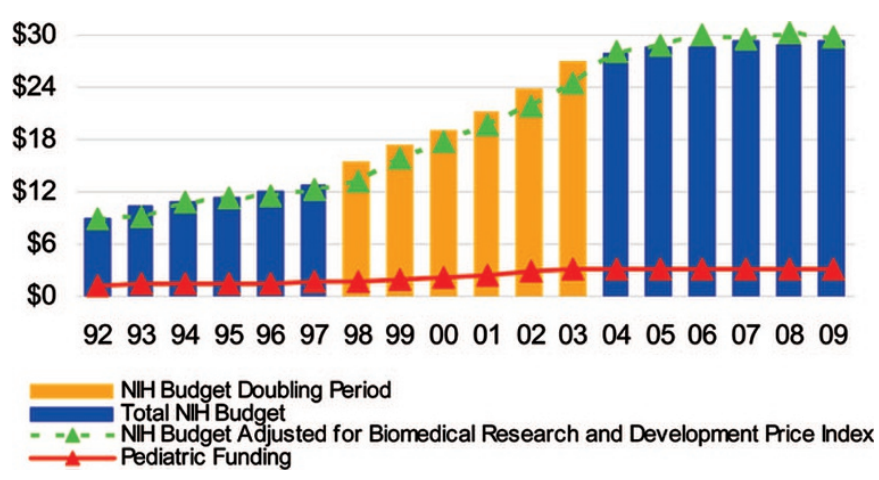

Figure 2. National Institutes of Health Budget and Pediatric Research Funding (in billions), FY 1992-2009. Congressional Appropriations (FY 1993-2007; FY 2008-2009 estimates); Pediatric Funding (FY 1993-2007; FY 2008-2009 estimates). Reported in nominal dollars.

and FY 2003 (to \$27.3 billion), an extraordinary commitment compared with the previous four decades during which the NIH budget doubled every 10 years. During the "doubling era," NIH appropriations increased at an average annual growth rate of $14.7 \%$. Pediatric research funding increased by an average annual rate of $12.8 \%$ - very similar to the overall NIH rate. In FY 2000, pediatric research funding was 18\%, actually exceeding the NIH growth rate (Fig. 2). In the final year of the doubling period (FY 2003), however, increases in pediatric funding $(8.4 \%)$ did not keep pace with the overall NIH appropriation (16.2) percent increase. Overall, pediatric research funding increased by $82.4 \%$ in nominal amounts during the doubling period. Indeed, therefore, a rising tide lifted all boats at NIH, but the lift was not equitable-the proportion of the total NIH budget devoted to the pediatric research portfolio declined from 12.3 to $11.3 \%$ during the doubling period.

The "sinking feeling" era, FY 2004-2009. Although the doubling-era increase in congressional appropriations enabled NIH to fund record levels of new and total research projects and accumulate a substantial commitment base, the management of that base has made the NIH particularly vulnerable to the static funding levels in the most recent period. The overall $\mathrm{NIH}$ and pediatric-specific research funding annual growth rates dropped significantly to $3 \%$ and $1.6 \%$ in FY 2004, respectively (Fig. 2). During the "postdoubling" era (FY 2004-2009), NIH appropriations have increased at an average annual growth rate of $1.3 \%$; average annual pediatric research spending has increased even less, by only $0.3 \%$. Furthermore, as Figure 2 shows, although NIH and pediatric research funding continue to increase in nominal dollars, they actually decrease when accounting for biomedical inflation.

As Figure 3 shows, if we assume that the doubling of NIH appropriations had not occurred, but the NIH budget had increased at the pre-FY 1998 growth rate of $7.5 \%$, the resulting estimated NIH budget of ( $\$ 32.9$ billion) would surpass its current budget of ( $\$ 29.5$ billion) in FY 2009. Assuming pre-FY 1998 growth rates, the pediatric research portfolio of $\$ 2.8$ billion would almost equal its current (estimated) budget of $\$ 3.1$ billion in FY 2009 (Fig. 3). Thus, the most recent period has wiped out much of the gains of the doubling era 


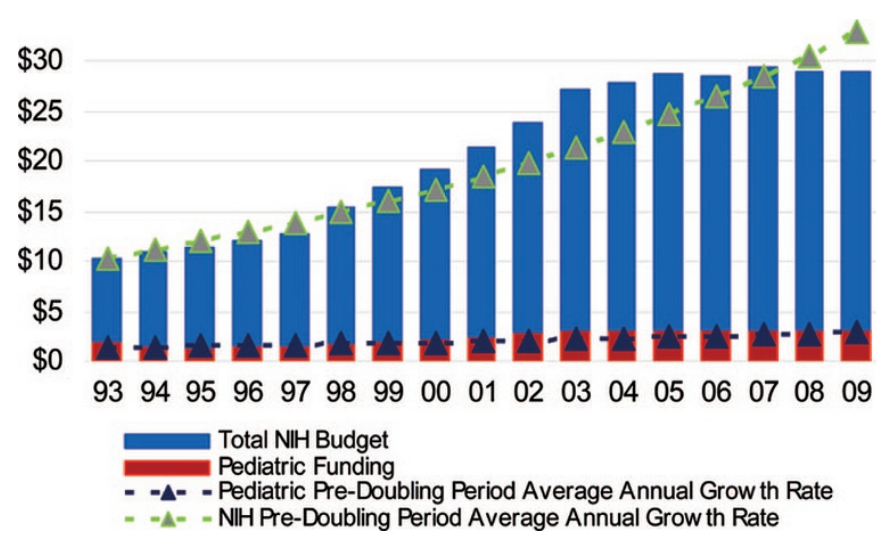

Figure 3. National Institutes of Health Appropriations and Pediatric Funding (pre-FY 1998) Assumptions (in billions) FY 1993-2009. Congressional appropriations (FY 1993-2008); pediatric research funding (FY 1993-2006, FY 2007-2008 estimates). Predoubling (FY 98) rates calculated by averaging annual growth rates from FY 1993-1997.

and the important associated increases in pediatric research funding.

\section{"No Growth" at NICHD and Its Impact on the Individual Pediatric Researcher}

The NICHD budget grew by an annual average rate of $6.6 \%$ between FY 1993 and FY 2007. During the most recent period, the NICHD budget has grown at a lower average annual growth rate of $0.7 \%$ compared with the overall NIH rate of $1.4 \%$ (Fig. 4). Actually, this downward trend has been true since FY 2001. According to Dr. Duane Alexander, the NICHD director, "When the (doubling) period ended, we hoped for a "soft landing" (for example, a slowed funding annual growth rate of about $5-6 \%$ ), but the actual rate is zero or even negative when you account for inflation." 10 The NICHD's $1 \%$ average annual growth rate is far below biomedical inflation for this period (Fig. 5).

The trickle down effect of minimal increases in NICHD appropriations during the most recent period, especially when adjusted for biomedical inflation, has had a dramatic and negative impact on the individual pediatric researcher. Although Congress in the CHA instructed NICHD to "increase the number and size of institutional training grants to institutions supporting pediatric training," and also to "increase the number of career development awards for health professionals who intend to build careers in pediatric basic and clinical research," this has proven daunting in the most recent period. Although the number of grants funded has not been reduced as much as the budget trends might indicate, the pediatric researcher is looking at less capacity to conduct research even when funded, not just by increased inflation, but by budget cuts per grant (according to NICHD staff, these cuts can range from 10 to up to $35 \%$ ). Fewer grants and fewer dollars per grant are not encouraging to young pediatric trainees who are considering a career in research. For selected diseases, condi-

\footnotetext{
${ }^{10}$ Eunice Kennedy Shriver National Institute of Child Health and Human Development National Institutes of Health Meeting with Dr. Duane Alexander, Director, April 17, 2008 .
}

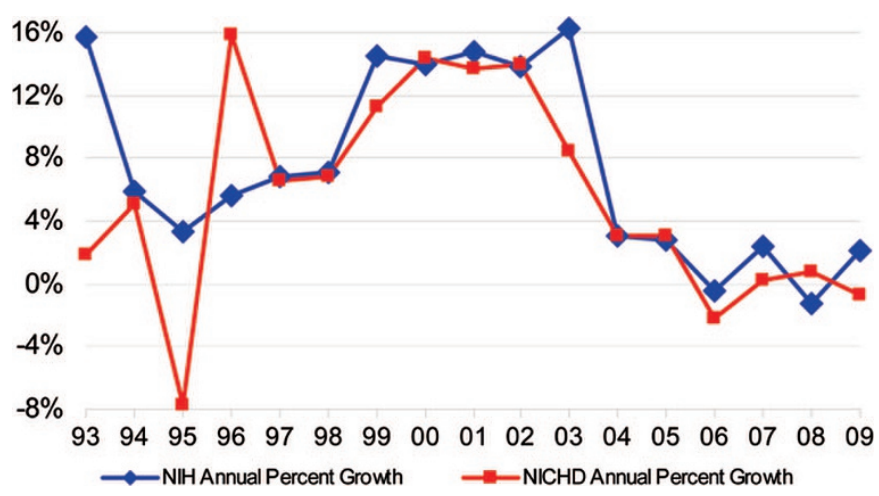

Figure 4. National Institutes of Health and NICHD Budget Annual Percent Growth Rates, FY 1993-2009. Congressional Appropriations (FY 19932007; FY 2008-2009 estimates). Percent change over previous FY in nominal dollars.

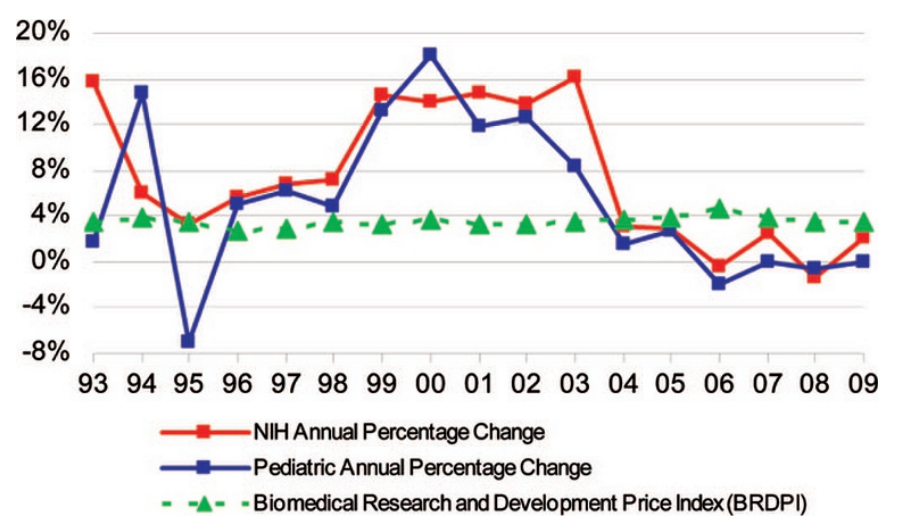

Figure 5. National Institutes of Health and Pediatric Research Funding Annual Growth Rates Relative to BRDPI, FY 1993-2009. Congressional appropriations (FY 1993-2007; FY 2008-2009 estimates); pediatric funding (FY 1993-2007; FY 2008-2009 estimates); BRDPI, FY 1993-2009.

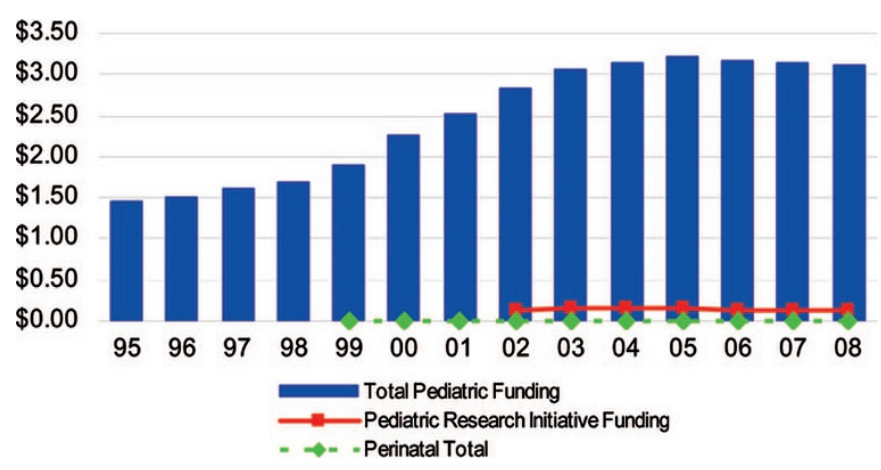

Figure 6. Pediatric research initiative (PRI) funding and perinatal funding relative to total pediatric research funding (in billions), FY 1995-2008.

tions, and research areas, the impact has been significant. For example, "perinatal period" grants based on actual grants, contracts, research conducted at NIH, and other mechanisms of support for all of NIH have decreased from 832 in 2004 to an estimated $761(-8.5 \%)$ for 2009 (see also Fig. 6 for trends in perinatal funding relative to the pediatric portfolio). Similar downward trends have occurred for NIH grants for teen pregnancy, childhood leukemia, pediatric AIDS, and child abuse and neglect research (15).

The number of successful NICHD institutional training grants (T32s) for research and academically oriented pediatric 
trainees has hardly changed over the past several years, from 30 grants in 2003 (39\% of applications) to 32 in 2007 (40\% of applications), although the number of trainee positions actually has increased, from 716 total positions per year (143 new) in 2003 to 771 total positions per year (159 new) in 2007. At the same time, however, the number of postdoctoral Ruth L. Kirschstein-National Research Service Award (NRSA) "individual" fellowships (F32s) has decreased from 43 to 21 at NICHD, with a decrease in application success rate from 48.3 to $16.3 \%$. Furthermore, NIH NRSA stipends have not increased significantly for over 5 years, surely a deterrent to young scientists or a major additional cost to their institutions should they try to keep up even with inflation, let alone increase their financial support for stipends. The increase in the number of applicants for Pediatric Research Loan Repayment Program grants has led to a much lowered funding percentile despite a larger total number of grants funded, a potential deterrent to new applications in that investigators tend to focus more on chance of success rather than number of applications funded (Appendix, online at www.pedresearch.org).

The funding pay-line score (study section score that a grant must be scored below, i.e., "better than") to receive funding for career development awards (K awards) at NICHD has decreased from 177 to 135 over this period. Similarly, the highest funded score for $\mathrm{K}$ awards has decreased from 184 in 2003 to 159 in 2007, as has the total number of $\mathrm{K}$ awards funded per year, from 53 to 48 (and percentage of funded "new" KO8 awards from 65.4 to $39.1 \%$ ). Furthermore, new KO8 awards have decreased from 17 in 2003 to only 8 in 2007. These downward trends in grant application success have occurred despite a major successful effort by NICHD to increase the types of $\mathrm{K}$ awards over the past 8 y (e.g., K23 funding has increased from 13 grants, $36.1 \%$ success, in 2003, to 25 grants, $48.1 \%$ success, in 2007), with similar trends for other K awards. Similarly, NICHD-funded NRSA predoctoral positions actually have increased, from 359 in 2003 to 422 in 2007, although the promise of this improvement in attracting beginning scientists at the predoctoral level fades in light of the reduction in NICHD postdoctoral NRSA positions, from 346 in 2003 to 339 in 2007 (Appendix, online at www.pedresearch.org).

For research projects, the funding percentile for the total number of RO1 research project grants (RPGs) at NICHD has declined from 21.0 in 2003 to 10.0 in 2006, although there was an increase in 2007 in the funding success rate and number of applications, primarily due to an increase in RO1 "new" principal investigator applications (which also led to an increase to 29.2 for the highest percentile score funded). This increase in the number of "new investigator" awards, which NICHD leadership said they would do, is an important accomplishment, but also a shift away from funding more senior investigators. The overall number of RO1s, which is the type of research project grant that senior investigators generally have relied on for their research support, is considerably reduced. The funding success for new, competing RO1s at NICHD has declined from $24.7 \%$ in 2003 (318 grants) to $21.2 \%$ (288 grants) in 2007, as has the total number of RO1 grants actually funded, from 1304 in 2003 to 1168 in 2007 (Appendix, online at www.pedresearch.org).

In contrast, funding at NICHD for R21s (generally grants representing new efforts by junior investigators or new areas of research for senior investigators and of more limited scope and cost than full RO1s), has increased, from 46 total grants (19 new) per year in 2003 to 155 total grants ( 90 new) per year in 2007 and with a pay-line percentile increasing to 20.0 in 2007 from 14.0 in 2004 and 2005 and from the all time low of 10.0 in 2006 (as well as an increase in the highest percentile score funded from 13.1 in 2004 to 26.2 in 2007). This trend represents a significant shift by NICHD to fund smaller (more focused), shorter duration, less expensive grants than RO1s. The recent trend to a higher cutoff score (i.e., a better score is needed to achieve funding) might reflect the increase in "new" principal investigators applying for funding, but also might indicate an effort by NICHD to fund more of this type of grant, both expected outcomes of encouraging this approach to funding. This trend in higher cutoff percentiles and study section priority scores also occurred at time when study sections were encouraged to broaden their scoring range of grants actually discussed at study section meetings. Interestingly, there also has been an increase in successful program project (PO1) grant application success at NICHD, from 8 of $21(30.8 \%)$ in 2003 to 16 of $38(42.1 \%)$ in 2007. The impact of this increase in PO1 funding on the average scientist funded through NICHD is not clear (Appendix, online at www. pedresearch.org).

Overall, therefore, funding for all of NIH and particularly at NICHD for pediatric trainees, junior investigators, and senior scientists has not increased and in many cases has decreased since the doubling period, despite some strong gains in certain funding areas and by certain funding mechanisms. The potential for successfully completing the transition from research training to research career development to independent investigation, by whatever grant mechanisms used, is now less promising.

\section{The Hard Landing and the End of a Decade, FY 2008-2009}

In January 2008, NIH—as specified in its appropriationallowed only a $1 \%$ inflation allowance to noncompeting research awards. This required a reduction to previously established commitments, which were based on a usual 3\% inflation allowance (16). This did not apply to career awards, small business innovation research/small business technology transfer grants (SBIR/STTR), and NRSA individual and institutional training grants. The office of the director (OD) encouraged ICs to attempt to "maintain the number of new investigators comparable with the average of the most recent 5 years" (14). Most recently, NIH made the difficult decision to eliminate any inflationary increases for RPGs. No inflationary increases are provided for direct, recurring costs in noncompeting RPGs in President Bush's FY 2009 budget, and the average cost of competing RPGs will remain at the FY 2008 level. 
Congress allocated $\$ 28.9$ billion to NIH for FY 2008 (a 1.3\% decrease over the FY 2007 funding). The NICHD received $0.63 \%$ more than its FY 2007 funding. President Bush's FY 2009 budget request of $\$ 29.2$ billion for NIH is a $1.2 \%$ increase over the FY 2008 appropriation. The proposed increase for NICHD in the president's FY 2009 budget is ( $\$ 1.256$ billion)—a $0.71 \%$ decrease over FY 2008. The NIH OD budget also does not support funding to continue the NCS in FY 2009. The public policy council (PPC), a legislative advocacy effort of the American Pediatric Society, the Association of Medical School Pediatric Department Chairs, and the Society for Pediatric Research, joined advocacy efforts led by the Ad Hoc Group for Medical Research and requested an overall NIH budget increase of $\$ 1.9$ billion (a $6.5 \%$ increase), for a total of $\$ 31.1$ billion in FY 2009. ${ }^{11}$ The friends of NICHD, a coalition of more than 100 organizations representing scientists, physicians, health care providers, patients, and parents concerned with the health and welfare of women, children, families, and people with disabilities, called for an appropriation of $\$ 1.34$ billion for NICHD in the FY 2009 budget, a 6.6\% increase over FY 2008. The "friends" also urged the committee to provide $\$ 192.3$ million in new funding for the NCS in FY 2009.

\section{Conclusions and Recommendations}

Many observers of the US biomedical research portfolio predicted that annual growth rates below 6 to $8 \%$ would erode the gains of the doubling era. Biomedical research inflation tends to exceed the consumer price index (CPI) by approximately $1.5 \%$ per year (17). As Figure 5 shows, the NIH budget would have needed to grow by at least 3.5\% (FY 2005 and FY 2006), 3.7\% (FY 2007), and 3.8\% (FY 2008) just to keep pace with biomedical inflation (according to estimates from the FY 2004 to 2008 biomedical research and development price index, or BRDPI). The actual annual growth rates for NIH appropriations were $2.8 \%$ (FY 2005), $-0.4 \%$ (FY 2006), and $2.4 \%$ (FY 2007) respectively. Between FY 2008 and FY 2009, $\mathrm{NIH}$ appropriations are projected to increase by $2.4 \%$, whereas pediatric research funding is projected to decline by $0.1 \%$. Unless Congress provides annual appropriations increases that will exceed the BRDPI, NIH and pediatricspecific commitments will become increasingly vulnerable.

Several recommendations are appropriate to protect against further erosion of the pediatric research portfolio and to implement a number of unfulfilled commitments to strengthen our investments in pediatric research.

\section{Fund the PRI With Specific Congressional Appropriations}

Intending that the PRI should be supported with "dedicated, identifiable dollars that represented new funding," Congress authorized $\$ 50$ million for the NIH OD to support the PRI in

\footnotetext{
${ }^{11}$ Five medical research advocacy groups compose the Ad Hoc Group for Medical Research, including: the Campaign for Medical Research (CMR), the Federation of American Societies for Experimental Biology (FASEB), the National Health Council (NHC), and Research!America.
}

FY 2001. Because the CHA became effective after the FY 2001 appropriations cycle, the $2001 \mathrm{FY}$ appropriations did not include any dedicated PRI funding. No funds have been appropriated by Congress specifically for the PRI since $2000 .{ }^{12}$ Consequently, the NIH funded the PRI by 1 ) a onetime, \$5 million distribution from the NIH Director's Discretionary Fund (FY 2002); and 2) individual and collaboratively-funded IC grants and contracts within an existing IC's annual budget. If the original legislative intent was that the PRI should be supported with dedicated, identifiable dollars that represent new funding in the reporting year, specific appropriations to the PRI in the OD and in consultation with the interinstitute committee on pediatric research is the only mechanism by which the PRI can expand beyond its "fixed" percentage of the overall pediatric research funding portfolio (Fig. 6).

\section{Support the NIH Child Inclusion Policy and Report on Its Performance}

With a static proportion of total NIH funds awarded to the pediatric research portfolio over almost two decades, it remains important to include children in all relevant clinical research. There has been no effort to evaluate the impact of or develop performance indicators for NIH's child inclusion guidelines. Because children are counted in the total numbers of research subjects along with adults, retrospective evaluation may be difficult.

It is important-if only prospectively-to know whether NIH guidelines have been effective and to recommend ways to strengthen the inclusion of children in future research.

\section{Continue to Fund the NCS With New and Targeted Appropriations}

The \$3.2 billion total cost of the NCS was intended to follow 100,000 children over 20 years. Although the early planning stages (FY 2000-2006) relied on internal allocations of dollars from within NICHD, NIEHS, CDC, and Environmental Protection Agency (EPA) budgets (more than $\$ 50$ million), there were no specific or additional congressional appropriations for the actual startup and planning phase (18). President Bush's FY 2007 budget request specifically directed NICHD to shut down all NCS operations, including the pilot study of 900 expectant mothers that was already under way (19). Congress, under House Appropriations Committee Chairman David Obey (D-Wis.), appropriated funds for FY 2007 (\$69 million) and FY 2008 (\$110.9 million) to continue the first phase of implementation of the NCS (20). To insulate the NICHD budget from increasing NCS funding requirements, Congress transferred funding for the NCS from the NICHD to the OD, which did not impact the day-to-day

\footnotetext{
${ }^{12}$ According to a key staffer familiar with the original CHA debate, Congress neve intended to make earmarked appropriations, consistent with its usual practice of funding ICs but not disease areas or subpopulations. Accordingly, "it was expected that NIH would allocate dollars from within its overall budget to fund research consistent with the PRI."
} 
management of the study. The president's FY 2009 budget request did not include any funding for the NCS.

The National Research Council (NRC) released a review of the research plan for the NCS in May 2008 and concluded that while the NCS offers an excellent opportunity to examine the effects of environmental influences on child health and development, there are "important weaknesses and shortcomings in the research plan that diminish the study's expected value below what it might be" (21). Without specific congressional appropriations in FY 2009, it is highly unlikely that the NCS can continue or make the type of improvements recommended by the NRC panel. The worst possible outcome of this major study would be, because of under funding, to end up with insufficient numbers of subjects and samples to generate and to provide insight into hypotheses about the mechanisms and causes of diseases and their progression over time.

\section{Support a NIH Pediatric Roadmap and Translation Research Program}

It is important to recognize that the data we report as part of the NIH pediatric research portfolio include support for research in developmental biology and clinical pediatrics. Thus, developmental biology alone could account for any funding increases within the overall pediatric portfolio. Although work in this area may lead to new insights into the pathophysiology of diseases that affect infants and children and hence to new ways to diagnose and treat them, some clinically-oriented researchers remain concerned that we are not applying what we already know. We offer a few recommendations.

We need to support further integration of research efforts into centers where basic and clinical scientists conduct research and care for children with complex medical needs and collaborate to produce high-quality outcome-based clinical and basic science research. New funding added specifically to NICHD and other IC's targeted to basic research (RO1s and $\mathrm{R} 21 \mathrm{~s}$ ) and research training ( $\mathrm{K}$ awards) in fundamental research in developmental medicine and biology would be highly valuable, both in providing research opportunities to help determine the basic mechanisms of disease and treatments, as well as the training necessary to produce new investigators to carry out the research. Second, the new Clinical-Translational Science Award program, which is replacing the previous NCRR Clinical Research Centers, should have specific funds allocated for child and maternal clinical translational research, providing increased opportunities for clinician-scientists to translate discoveries of disease mechanisms into therapies that then can be spread into the community. Third, the NIH roadmap should include specific support for pediatric-related research.

Finally, new appropriations should be provided for the National Pediatric Research Consortia Bill, recently introduced in the Senate and House, that would establish up to 20 pediatric research consortia, consisting of cooperative arrangements among institutions with core research capacities to support basic, clinical, behavioral, social, and translational research, as well as specific research training and advanced diagnostic and treatment methods in children. Each individual consortium will be a multi-institution network with one leading pediatric medical center at the hub, reaching out to and working with numerous other children's hospitals and health organizations to conduct basic and translational pediatric research. This model will maximize the efficiency and effectiveness of NIH resources that are allocated, as well as create a wider pool for recruitment of patients for the clinical trials that will be conducted. There also will be collaboration and sharing of results among the various consortia, putting an intense focus on pediatric research and creating lines of communication across the entire US pediatric research community for the first time.

\section{Highlight the Life-Cycle Focus of Pediatric Research}

Some might argue that an "age-specific" focus in the NIH roadmap or other targeted pediatric collaboration is misguided. We too reject the tendency to define health issues as distributional problems among age groups at a slice in time. For example, data clearly demonstrate that adult health risks (particularly obesity, diabetes, cardiovascular disease, cancer, and immune disease) are influenced by life events before and throughout pregnancy as well as during childhood, including, for example, disorders of fetal growth, exposure to maternal drugs and environmental toxins, and excesses and deficiencies of specific nutrients and hormones. Such support should enhance research done in conjunction with obstetricians and maternalfetal medicine specialists as well, recognizing that a healthy mother has a much better chance of producing a healthy infant, child, and adolescent, as well as a future healthy adult. Finally, an understanding of the relationship between genetic variation and disease risk promises to change significantly the prevention and treatment of childhood and adult illnesses. In sum, the pediatric research community needs to emphasize the potential for investments in pediatric research to influence health and human development across the life cycle. It is imperative that national policymakers, with leadership, encouragement and support of the pediatric research and clinical community, put on their agenda to increase investments in research into the developmental processes and mechanisms that influence the emergence and course of disorders from birth through adolescence and into young adulthood.

Acknowledgments. The authors gratefully acknowledge the helpful reactions of Dr. Duane Alexander, director of the Eunice Kennedy Shriver NICHD, and the ongoing assistance of Lisa Kaeser, NICHD Office of Program and Public Liaison. The authors also acknowledge the research assistance of Caitlin Winwood, a public policy and economics undergraduate student, and the editorial assistance of Jessica Dorrance, a Research Associate, at UNC-CH.

\section{REFERENCES}

1. U.S. Census Bureau 2006 American Community Survey (ACS). U.S. Census Bureau, Washington, DC

2. Carraso A, Steuerle CE, Reynolds G 2007 Kids Share 2007: How Children Fare in the Federal Budget. Urban Institute. Available at http://www.urban.org/url. $\mathrm{cfm} ? \mathrm{ID}=411432$. Accessed September 2, 2008

3. Stiehm ER 1996 Pediatric Research: National Institutes of Health support in the 'steady-state' decade, 1983-1993. Arch Pediatr Adolesc Med 150:971-974 
4. McCabe LL 1998 National Institutes of Health support for research and training: future of pediatric scientists. Arch Pediatr Adolesc Med 152:839-842

5. Holdsworth MT 2003 Pediatric drug research-the road less traveled. Ann Pharmacother 37:586-591

6. Gitterman DP, Greenwood RS, Kocis KC, Mayes BR, McKethan AN 2004 Did a rising tide lift all boats? The NIH budget and pediatric research portfolio. Health Aff (Millwood) 23:113-124

7. Gross CP, Anderson GF, Powe NR 1999 The relationship between funding by the National Institutes of Health and the burden of disease. N Engl J Med 340:18811887

8. Smyth RL, Weindling AM 1999 Research in children: ethical and scientific aspects Lancet 354:SII21-SII24

9. Campbell H, Surry SA, Royle EM 1998 A review of randomized controlled trials published in Archives of Disease in Childhood from 1982-1996. Arch Dis Child 79:192-197

10. U.S. House of Representatives Report No 2091995 104th Congress, 1st session, pp $80-81$

11. U.S. Department of Health and Human Services, Public Health Service, NIH April 1996 "Report on NIH Pediatric Research," pp 15

12. U.S. Department of Health and Human Services NIH Report to Congress: The FY 2002 Pediatric Research Initiative, 2003

13. U.S. Department of Health and Human Services, NIH Report to Congress: The FY 2006 Pediatric Research Initiative, 2008
14. Healy B 1994 Shattuck lecture-NIH and the bodies politic. N Engl J Med 330:1493-1498

15. U.S. Department of Health and Human Services NIH 2008 Estimates of funding for various diseases, conditions, research areas. Available at: http://www.nih.gov/news/ fundingresearchareas.htm

16. U.S. Department of Health and Human Services NIH 2008 Fiscal policy for grant awards. Available at: http://grants.nih.gov/grants/guide/notice-files/NOT-OD-08036.html

17. U.S. Department of Health and Human Services NIH 2008 General budget information, price indexes. Available at: http://officeofbudget.od.nih.gov/ui/ GDP_FromGenBudget.htm

18. Check E 2004 Huge study of children aims to get the dirt on development. Nature 432:425

19. Vastag B 2006 Budget cuts put children's health study on chopping block. Nat Med $12: 720$

20. U.S. Department of Health and Human Services, NIH web site interagency and congressional funding for the National Children's Study; Wadman M 2007 Bush challenged on funding for children's study. Nature 446:240-241

21. National Academy of Science 2008 The National Children's Study Research Plan: a review (Free Executive Summary). Available at: http://www.nap.edu/catalog/ 12211.html 